Article

\title{
Bentonite Modified by Allylamine Polymer for Adsorption of Amido Black 10B
}

\author{
Wenjuan Guo ${ }^{1}$, Tingcheng Xia ${ }^{2}$, Meishan Pei ${ }^{3, *}$, Yankai Du ${ }^{3}$ and Luyan Wang ${ }^{3}$ \\ 1 Institute of Surface Analysis and Chemical Biology, University of Jinan, Jinan 250022, China; \\ chm_guowj@163.com \\ 2 Shandong Labor Vocational and Technical College, Jinan 250022, China; xiatingcheng@163.com \\ 3 School of Chemistry and Chemical Engineering, Shandong Provincial Key Laboratory of Fluorine Chemistry \\ and Chemical Materials, University of Jinan, Jinan 250022, China; 1287858357@163.com (Y.D.); \\ chm_wangly@ujn.edu.cn (L.W.) \\ * Correspondence: chm_peims@ujn.edu.cn; Tel.: +86-186-7829-0022; Fax: +86-531-8276-5475
}

Received: 30 December 2018; Accepted: 6 March 2019; Published: 15 March 2019

\begin{abstract}
The main object of this work is to remove Amido black 10B using a new type of bentonite-based adsorbent with cationic groups by the modification of polyallyl amines between the interlayers of bentonite. Fourier transform infrared, X-ray diffraction, thermogravimetric analysis, and scanning electron microscopy were used to characterize the functionalized bentonite. A series of batch adsorption experiments were performed. The maximum adsorption amount was $144.08 \mathrm{mg} \mathrm{g}^{-1}$ when the $\mathrm{pH}$ was 2 and the contact time was $120 \mathrm{~min}$. In addition, the equilibrium isotherm data were analyzed using Langmuir and Freundlich isotherm models, while only the Langmuir model could provide a high correlation. Therefore, this study provided a new functionalized bentonite as a low-cost adsorbent for dye removal from water.
\end{abstract}

Keywords: bentonite; adsorbent; polyallyl amines; Amido black 10B

\section{Introduction}

Water is an important resource. With the development of industry, water pollution is getting more serious. In the realm of water pollution, the industrial wastewater caused by the discharge of dyes is a non-negligible problem. Industrial wastewater discharged into rivers and lakes, and finally into the sea, creates a huge pollution problem. The use of dyes is unavoidable, as they can be found in many industrial fields, such as textiles, papermaking, plastics, food, rubber, and cosmetics. For example, crystal violet dye, the brightest dye, can cause human bladder cancer [1]. Rhodamine B can be harmful to the environment. In California, rhodamine B is considered a carcinogenic substance, and products with rhodamine B must have a warning label on the packaging [2]. Therefore, the concentration of dyes in wastewater must be reduced to the permissible limit for the sake of human health as well as environmental safety. Amido black 10B is one of the dyes most widely used in industry [3]. Zhang et al. investigated the adsorption of Amido Black 10B from aqueous solutions onto a $\mathrm{Zr}$ (IV) surface-immobilized cross-linked chitosan/bentonite composite [4]. The adsorption capacity was $418.4 \mathrm{mg} \mathrm{g}^{-1}$ at natural $\mathrm{pH}$ value and $298 \mathrm{~K}$. Wang et al. prepared porous chitosan doped with graphene oxide as a highly effective adsorbent for methyl orange and amido black 10B [5]. The adsorption capacity of AB10B was $573.47 \mathrm{mg} \mathrm{g}^{-1}$. Zhang et al. prepared a crosslinked quaternized chitosan/bentonite composite for the removal of Amino black 10B from aqueous solutions [6]. The maximum monolayer adsorption capacity was $990.1 \mathrm{mg} \mathrm{g}^{-1}$ at $298 \mathrm{~K}$ and natural $\mathrm{pH}$ in terms of the Langmuir model. Hu et al. investigated the simultaneous removal of $\mathrm{Cr}(\mathrm{VI})$ and Amido black 10B (AB10B) from aqueous solutions using quaternized chitosan-coated bentonite [7]. The maximum 
adsorption capacity of the modified bentonite, according to the Langmuir isotherm model, was $847.5 \mathrm{mg} \mathrm{g}^{-1}$ for AB10B at $298 \mathrm{~K}$. At present, the widely used technologies include advanced oxidation processes [8], adsorption [9-11] membrane filtration [12], and photocatalytic degradation [13]. Those technologies are expensive because of the specialist materials required. For example, membrane filtration technology requires an expensive membrane material that is not suitable for common use [14-17]. By comparison, adsorption is an efficient and relatively economical technology for the removal of dyes from wastewater. Among the adsorbents, chitosan and its derivatives have received considerable attention as flocculants in water treatment. Several chemical modification methods to prepare chitosan-based flocculants have been reported [18]. For use in practical applications, Li et al. prepared a chitosan magnetic composite adsorbent modified with a quaternary ammonium salt for the removal of $\mathrm{Cr}(\mathrm{VI})$ and methyl orange (MO) from water. This magnetic adsorbent after saturated adsorption could be rapidly separated from water [19]. Angelova et al. assessed the biosorption of Amido black 10B dye from aqueous solutions on magnetically modified sheaths of Leptothrix sp. in a batch system [20]. These methods allowed convenient control and adjustment of the structures of the obtained materials to meet the different practical requirements. Activated carbon materials are also traditional adsorbents that have been used in many fields. Whereas, with the increase in demand for commercial activated carbon materials, the price of activated carbon materials is becoming more expensive. As abundant, inexpensive, and environmentally friendly materials in nature, clays have potential value as adsorbents for the removal of dyes from wastewater. Yang et al. applied an acid-treated palygorskite as an adsorbent to remove various contaminants and it showed efficient performance in the adsorption of all three cationic dyes because of electrostatic interactions [21].

Bentonite (Bent), one of the most common clays, has been used in a variety of industrial fields as a catalyst, filler in polymer, cosmetics, and pharmaceuticals, because of its high surface area and swelling property [22]. The main clay mineral constituent of Bent is montmorillonite. Its crystal structure is shown in Figure 1: it is composed of one octahedral aluminate layer (termed as $\mathrm{O}$ ) sandwiched between two tetrahedral silicate layers (abbreviated as T), forming a TOT type [23]. The natural Bent has limited adsorption capability, which restricts its practical applications [24]. The reason might be the poor dispersibility of Bent in water. Bent should be modified with some functional groups to improve its adsorption capability for dyes.

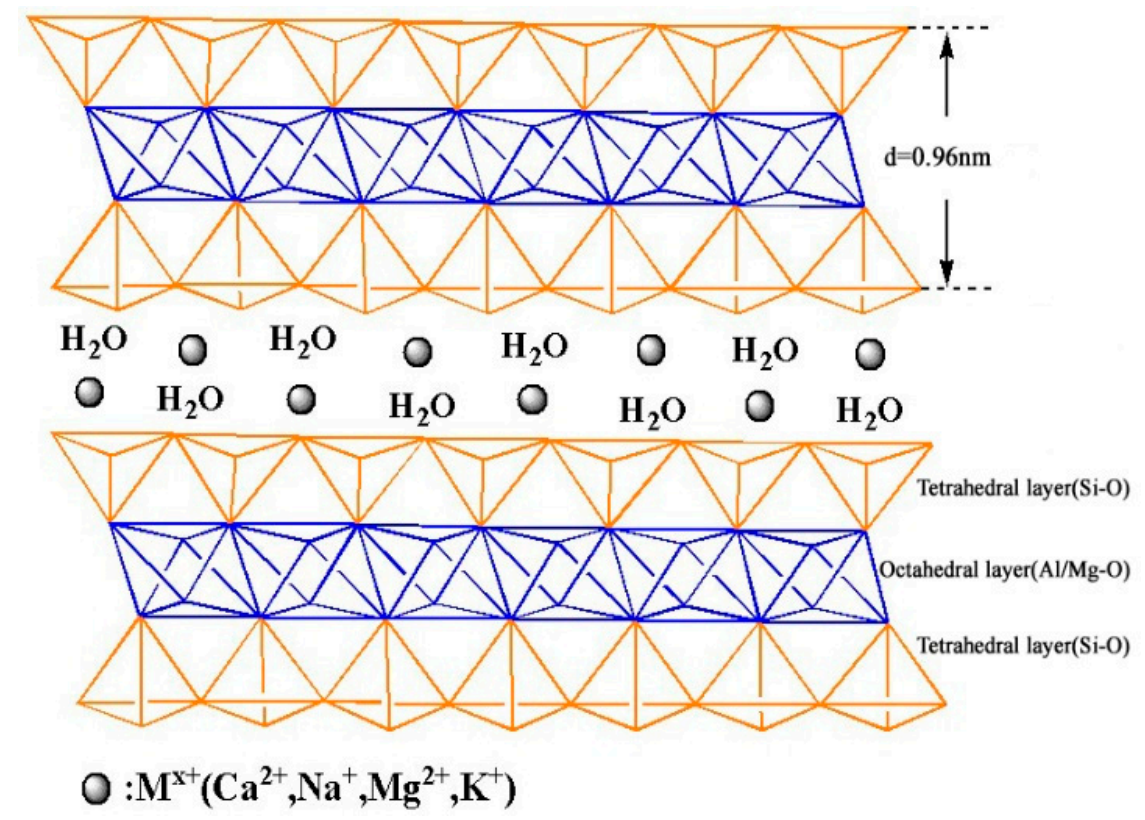

Figure 1. The structure of montmorillonite. 
In this study, Bent was designed to be modified with the cationic group polyallyl amines (PAA). The as-prepared material was characterized by X-ray diffraction (XRD), Fourier transform infrared spectroscopy (FTIR), thermal gravimetric analysis (TGA), and scanning electron microscopy (SEM). The novel material was used to adsorb Amido Black 10B as a representative of the anionic dyes. Batch adsorption experiments were used to evaluate the adsorption capacity of the novel adsorbent for AB10B. Experimental data were analyzed by adsorption isotherms and adsorption kinetics.

\section{Materials and Methods}

\subsection{Materials}

Bent was supplied by Weifang Zhenxing Bentonite Co. (Weifang, China). It was purified by dispersed into water for $3 \mathrm{~h}$ and then centrifuged. After being dried at $80^{\circ} \mathrm{C}$ in a vacuum oven, the product was obtained. Toluene, purchased from Laiyang Tieta Fine Chemical Factory (Laiyang, China), was used as the solvent. PAA, glutaraldehyde, and 3-aminopropyltriethoxysilane were obtained from Aladdin Industrial Corporation (Shanghai, China). Chemicals were analytical grade without further purification.

\subsection{Modification of Bent}

One gram of 3-aminopropyltriethoxysilane, the silane coupling agent, and $1.0 \mathrm{~g}$ of Bent were added into $50 \mathrm{~mL}$ of methylbenzene. The mixture solution was heated to $60^{\circ} \mathrm{C}$ and stirred for $5 \mathrm{~min}$. After being dried at $80{ }^{\circ} \mathrm{C}$ in a vacuum oven, the as-prepared solid was ground to a powder. Next, $1.0 \mathrm{~g}$ of the sample was added into $50 \mathrm{~mL}$ of deionized water, followed by adding $2 \mathrm{~g}$ of PAA and a certain amount of glutaraldehyde. At room temperature, the reaction was held steady for $5 \mathrm{~h}$. Subsequently, the precipitate was sequentially filtered and rinsed with deionized water. Being dried for $6 \mathrm{~h}$ at $80^{\circ} \mathrm{C}$ in a vacuum oven, the solid was grinded to pass through a 200 mesh sieve. The as-prepared product was represented as Bent-PAA.

\subsection{Characterizations}

XRD patterns were obtained using a BRUKER AXS D8 X-ray diffractometer (Karlsruhe, Germany). The $X$-ray generator was operated at $40 \mathrm{kV}$ and $40 \mathrm{~mA}$ using $\mathrm{CuK}_{\alpha}(\lambda=1.540598 \AA)$. Data were collected with a $\omega$ scan width of $0.02^{\circ}$. FTIR spectra were recorded on a PE Spectrum One spectrometer (Shelton, CT, USA). Thermal studies (TG/DTA) were conducted on Perkin Elmer (Shelton, CT, USA) in air at a heating rate of $10^{\circ} \mathrm{C} \mathrm{min}-1$. SEM was collected using a Philips XL-30 FEG SEM instrument at $25 \mathrm{kV}$ (Eindhoven, The Netherlands).

\subsection{Batch Adsorption Experiments}

The batch adsorption experiments were operated by a Dongpeng SHA-C water bath shaker (Jintan, China). The effect of experimental parameters, such as the initial concentration $\left(c_{0}\right)$ of $\mathrm{AB} 10 \mathrm{~B}, \mathrm{pH}$, experimental temperature $(T)$, and contact time $(t)$, on the adsorption amount was studied according to Table 1. Here, the adsorption amount of Bent-PAA for AB10B can be calculated by the following equation:

$$
q_{e}=\left(c_{0}-c_{e}\right) V / m
$$

where $c_{e}$ is the equilibrium concentration of $\mathrm{AB} 10 \mathrm{~B}$ in solution $\left(\mathrm{mg} \mathrm{L}^{-1}\right), V$ is the volume of solution (L), and $m$ is the mass of the adsorbent (g). All experiments were performed in triplicate and the results are reported as the mean \pm standard deviation. 
Table 1. Batch sorption experiments parameters.

\begin{tabular}{cccccccc}
\hline Adsorbent & $\boldsymbol{t}(\mathbf{m i n})$ & $\mathbf{p H}$ & $\boldsymbol{c}_{\mathbf{0}}\left(\mathbf{m g ~ L}^{-\mathbf{1}}\right)$ & $\boldsymbol{m}_{\mathbf{a}}(\mathbf{g})$ & $V_{\mathbf{s}}(\mathbf{m L})$ & $\boldsymbol{T}\left({ }^{\circ} \mathbf{C}\right)$ & $S(\mathbf{r p m})$ \\
\hline \multirow{3}{*}{ Bent-PAA } & 480 & $2-9$ & 200 & 0.03 & 30 & 25 & 200 \\
& $10-480$ & 2 & $100-200$ & 0.03 & 30 & 25 & 200 \\
& 480 & 2 & $50-400$ & 0.03 & 30 & $25-45$ & 200 \\
\hline
\end{tabular}

$m_{\mathrm{a}}, V_{\mathrm{S}}, T$, and $S$ represent the mass of adsorbent, the volume of solutions, experimental temperature, and rotational speed, respectively.

\section{Results and Discussion}

\subsection{Bent-PAA Characterization}

Figure 2 shows the XRD patterns of Bent and Bent-PAA. The distance between layers of bentonite can be determined based on the position of the characteristic reflection peak (001) in the XRD patterns. In Figure 2a, the XRD pattern of Bent had a characteristic (001) reflection at approximately $7.10^{\circ}$ (20) [25], while the peak position shifted to $5.51^{\circ}(2 \theta)$ after Bent was modified with PAA. Results calculated by the Bragg equation showed that the shift in the distance between layers was from $1.24 \mathrm{~nm}$ (Bent) to $1.60 \mathrm{~nm}$ (Bent-PAA) when Bent was modified with PAA. It can be inferred that the monolayer of PAA molecules was arranged parallel to the interlayer space of Bent.

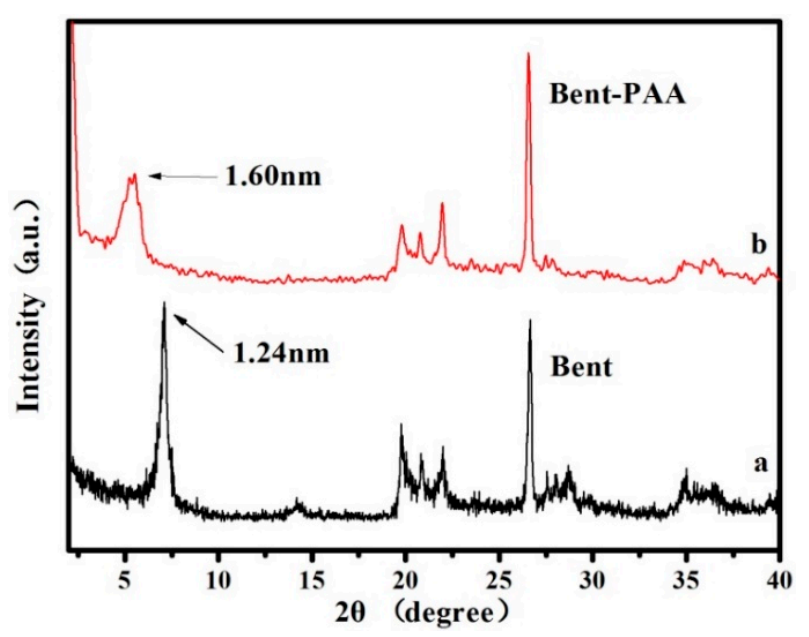

Figure 2. The XRD patterns of Bent-PAA (a) and Bent (b).

Figure 3 shows the FTIR spectra of Bent and Bent-PAA. In Figure 3a, the bands at 3623 and $3423 \mathrm{~cm}^{-1}$ were attributed to the stretching vibration of structural hydroxyls ( $\mathrm{Si}-\mathrm{OH}, \mathrm{Al}-\mathrm{OH}$ ) and the physical absorption of water $(\mathrm{H}-\mathrm{OH})$, respectively $[26,27]$, with a corresponding deformation band (H-O-H) at $1638 \mathrm{~cm}^{-1}$ [28]. The characteristic bands at 1038, 798, 519, and $465 \mathrm{~cm}^{-1}$ were ascribed to $\mathrm{Si}-\mathrm{O}$ stretching vibration from the $\mathrm{Si}-\mathrm{O}-\mathrm{Si}$ tetrahedron, $(\mathrm{Al}, \mathrm{Mg})-\mathrm{OH}$ vibration mode, $\mathrm{Si}-\mathrm{O}-\mathrm{Al}$ deformation, and the angular deformation of $\mathrm{Si}-\mathrm{O}-\mathrm{Si}$, respectively [29]. Spectra of Bent-PAA possessed an obvious peak at $1514 \mathrm{~cm}^{-1}$ caused by the bending vibrations of $-\mathrm{NH}_{2}$ while Bent did not. The peak of $-\mathrm{CH}_{2}$-asymmetric stretching at $2934 \mathrm{~cm}^{-1}$ also confirmed the successful modification of Bent with PAA. 


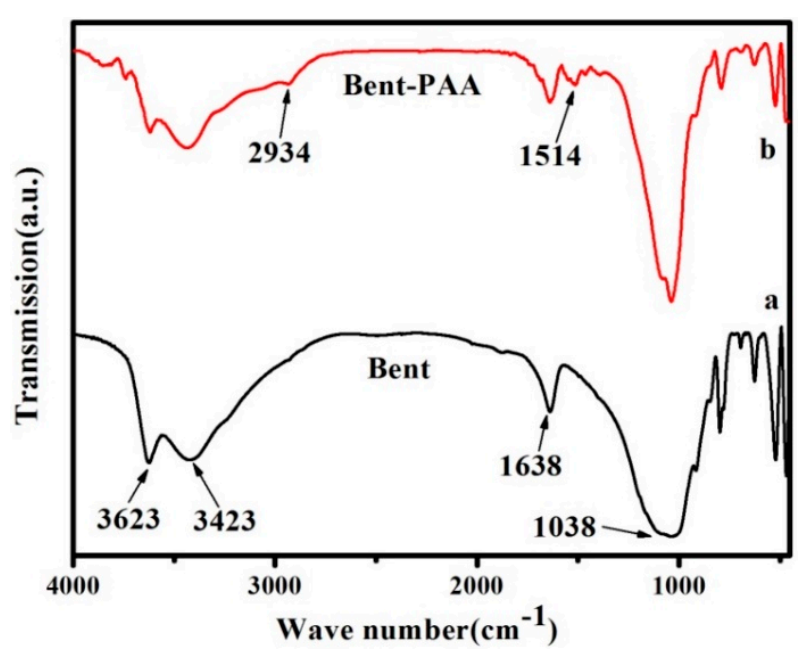

Figure 3. The FTIR spectra of Bent (a) and Bent-PAA (b).

The thermodynamic stability of Bent and Bent-PAA has been investigated by thermogravimetric analysis (TGA). In Figure 4a, a $6 \%$ weight loss of Bent appeared at $680{ }^{\circ} \mathrm{C}$, caused by the dehydroxylation of the silicate layers, while the weight loss of Bent-PAA was much greater than that of Bent, attributed to the loss of PAA molecules modified on Bent. The results directly reflected the successful modification of PAA on Bent.

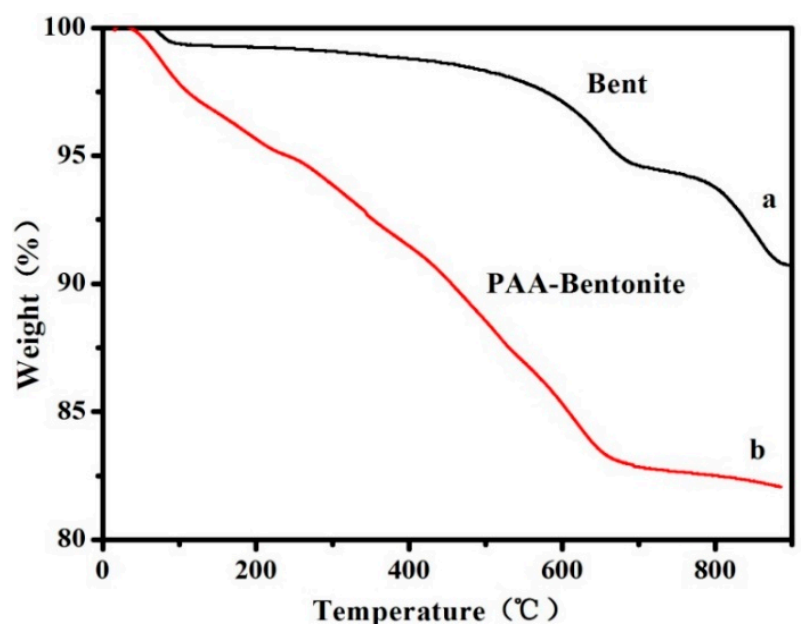

Figure 4. The TGA curves of Bent (a) and Bent-PAA (b).

In order to obtain information about the shape and size, SEM measurements of Bent and Bent-PAA have been done. Results are shown in Figure 5. Compared with the surface of Bent, that of Bent-PAA showed a much more regular, layered structure. Obviously, considerably larger cracks were formed. 


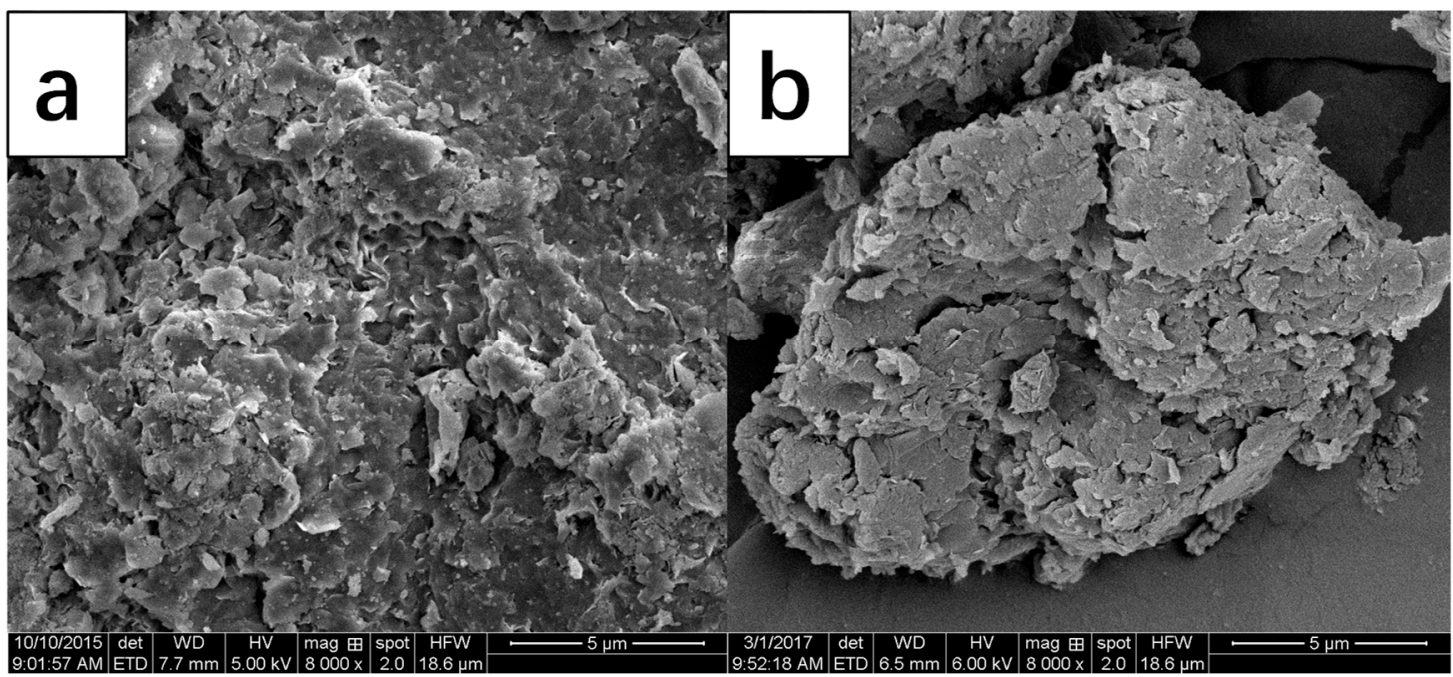

Figure 5. SEM images of Bent (a) and Bent-PAA (b).

\subsection{Adsorption Results}

\subsubsection{Effect of $\mathrm{pH}$}

The effect of solution $\mathrm{pH}$ from 2.0 to 9.0 on the adsorption amount of Bent and Bent-PAA has been investigated. Results are shown in Figure 6. The adsorption amount of Bent for AB10B was nearly zero within the whole designed $\mathrm{pH}$ range, indicating that Bent had no adsorption ability for AB10B. Compared with Bent, the adsorption amount of Bent-PAA for AB10B obviously increased and depended on the $\mathrm{pH}$ value. As for Bent-PAA, $q_{e}$ decreased quickly within the value of $\mathrm{pH}$ ranging from 2.0 to 4.0. After that, $q_{e}$ decreased gradually. This phenomenon may be caused by the effect of hydrogen ions on the positive sites of the adsorbent. At a lower $\mathrm{pH}$, the more hydrogen ions in solution made the surface of Bent-PAA covered with more positive charges, which was beneficial for the electrostatic attraction between the positive charges of Bent-PAA and the negative charges of AB10B. When $\mathrm{pH}$ increased, the number of positive charges loaded on the surface of Bent-PAA reduced, which led to a decrease in the number of interaction sites of Bent-PAA with AB10B. Thus, the adsorption amount of Bent-PAA for AB10B decreased with the rise in $\mathrm{pH}$. Results demonstrated that the graft of PAA contributed to the improvement of adsorption amount.

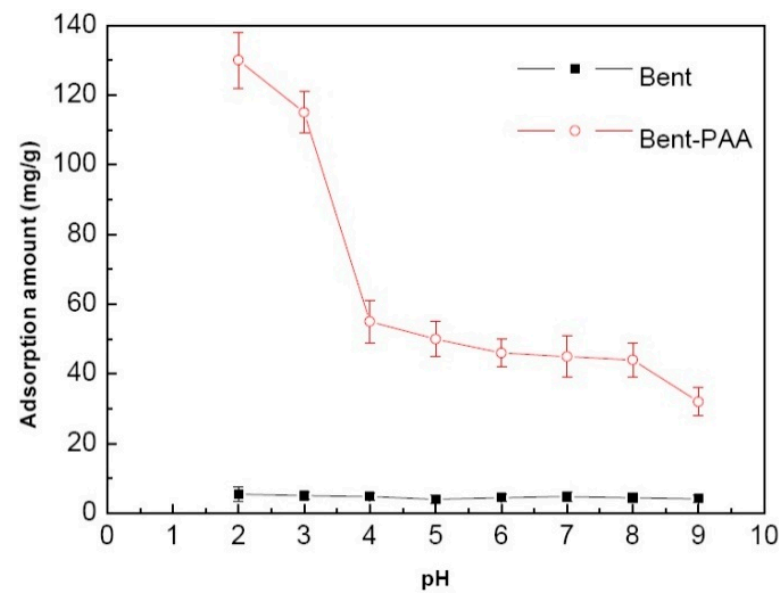

Figure 6. Effect of the solution $\mathrm{pH}$ on the adsorption amount of Bent and Bent-PAA for AB10B. Adsorption conditions: adsorbent dosage: $1.0 \mathrm{~g} \mathrm{~L}^{-1}$; at $298 \mathrm{~K}$ and $\mathrm{pH} 2-9$; Contact time: 480 min; Dye concentration: $200 \mathrm{mg} \mathrm{L}^{-1}$. 


\subsubsection{Effect of Contact Time}

The effect of contact time on the adsorption amount of Bent-PAA for AB10B has been investigated as shown in Figure 7. In the first $60 \mathrm{~min}$, the adsorption amount increased quickly and gradually reached equilibrium. It seems clear that, during the first period, the bare surface was easier to cover with $\mathrm{AB} 10 \mathrm{~B}$, which caused the obvious increase in the adsorption amount of $\mathrm{AB} 10 \mathrm{~B}$. After that, the next $A B 10 B$ molecules should choose the limited bare surface to be loaded, which led to a decrease in the adsorption rate.

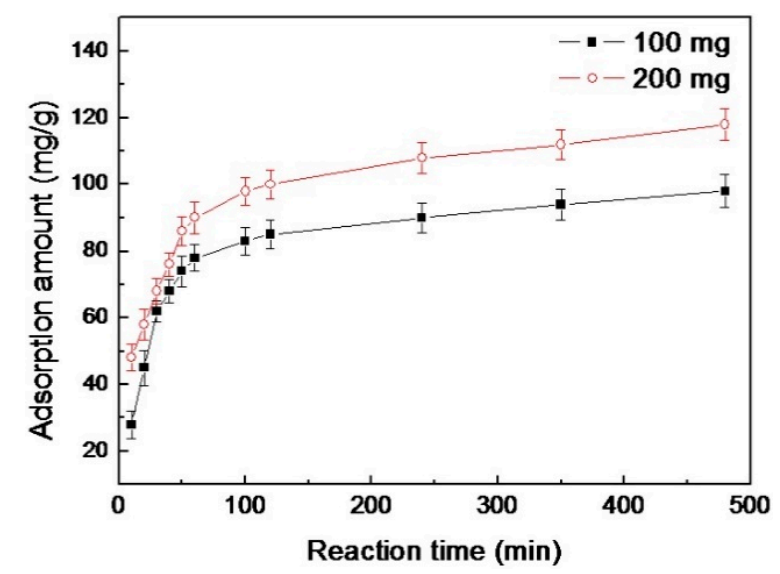

Figure 7. Effect of contact time of Bent-PAA with AB10B on the adsorption amount. Adsorption conditions: adsorbent dosage: $1.0 \mathrm{~g} \mathrm{~L}^{-1}$; at $298 \mathrm{~K}$ and $\mathrm{pH} 3$; Contact time: 0-480 min; Dye concentration: 100 and $200 \mathrm{mg} \mathrm{L}^{-1}$.

\subsubsection{Effect of Initial Concentration of AB10B}

The effect of initial concentration of $\mathrm{AB} 10 \mathrm{~B}$ on the adsorption amount of Bent-PAA has been investigated at different temperatures $\left(25,35,45^{\circ} \mathrm{C}\right)$. Results are shown in Figure 8 . The adsorption amount of $A B 10 B$ increased quickly within the initial period with the increase of initial concentration of $\mathrm{AB} 10 \mathrm{~B}$ and then gradually became more stable. When the concentration of $\mathrm{AB} 10 \mathrm{~B}$ was in a lower concentration range, the ratio of the absorption sites of Bent-PAA to AB10B was higher, leading to a higher removal rate of $\mathrm{AB} 10 \mathrm{~B}$. When the concentration of $\mathrm{AB} 10 \mathrm{~B}$ was higher, the adsorption sites were gradually saturated, which led to the relatively lower adsorption rate of AB10B on Bent-PAA.

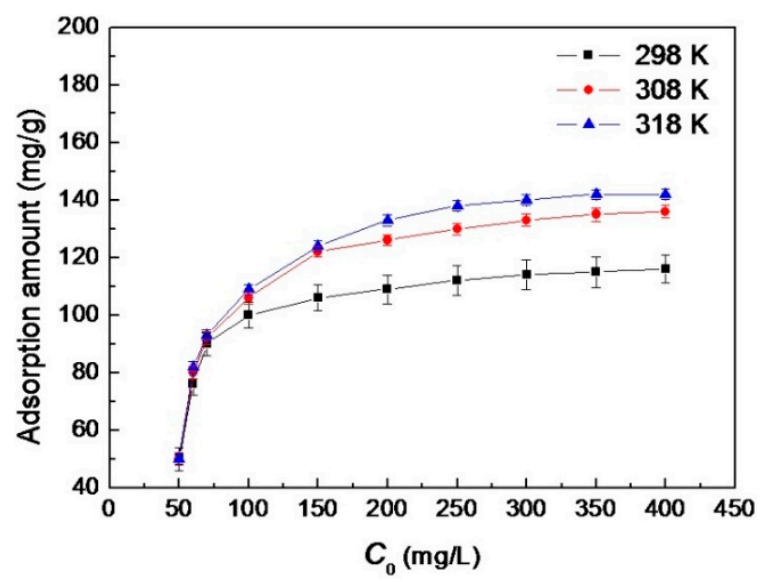

Figure 8. Effect of $c_{0}$ of $\mathrm{AB} 10 \mathrm{~B}$ on the adsorption amount of Bent-PAA for $\mathrm{AB} 10 \mathrm{~B}$ at different temperatures. Adsorption conditions: adsorbent dosage: $1.0 \mathrm{~g} \mathrm{~L}^{-1}$; at 298,308 and $318 \mathrm{~K}$ and $\mathrm{pH} 3$; Contact time: $480 \mathrm{~min}$; Dye concentration: $50-400 \mathrm{mg} \mathrm{L}^{-1}$. 


\subsubsection{Effect of Temperature}

The effect of temperature on the adsorption amount of Bent-PAA for AB10B can also be seen in Figure 8. The adsorption amount of Bent-PAA for AB10B was higher at higher temperatures, which indicated that the adsorption interaction was an endothermic process. Moreover, the thermodynamic parameters for the adsorption processes have been calculated according to a previous method [19]. Here, $\Delta G$ was $-23.94 \mathrm{~kJ} \mathrm{~mol}^{-1}, \Delta H$ was $-14.22 \mathrm{~kJ} \mathrm{~mol}^{-1}$ and $\Delta S$ was $35.62 \mathrm{~J} \mathrm{~mol}^{-1} \mathrm{~K}^{-1}$. The negative values of $\Delta G$ and $\Delta H$ with the positive value of $\Delta S$ indicated that the adsorption process was spontaneous and exothermal, driven by the increase in entropy.

\subsubsection{Adsorption Isotherm}

Here, the adsorption data have been fitted to a couple of widely used adsorption isotherms, namely, the Langmuir and Freundlich adsorption isotherm models. Langmuir adsorption isotherm can be expressed as follows:

$$
\frac{c_{e}}{q_{e}}=\frac{1}{\mathrm{~K}_{L} q_{m}}+\frac{c_{e}}{q_{m}},
$$

where $c_{e}$ is the equilibrium concentration of adsorbate $(\mathrm{mg} / \mathrm{L}), q_{e}$ is the adsorption amount of adsorbent $(\mathrm{mg} / \mathrm{g}), q_{m}$ is the maximum adsorption amount in theory, and $\mathrm{K}_{L}$ is the Langmuir constant related to the affinity of binding sites.

However, the Freundlich model is an empirical formula suitable for heterogeneous surfaces. The corresponding equation is given below:

$$
\ln q_{e}=\ln \mathrm{K}_{F}+1 / \mathrm{n} \ln c_{e},
$$

where $\mathrm{K}_{F}$ and $\mathrm{n}$ are Freundlich constants. $\mathrm{K}_{F}$ indicates the relative adsorption capability and $\mathrm{n}$ is related to adsorption intensity.

The adsorption data were fitted to Equations (2) and (3) and the linear simulations were shown in Figure 9. In addition, corresponding isotherm parameters for the two models are summarized in Table 2. The correlation of the Langmuir model was stronger than that of the Freundlich model based on the regression coefficients $\left(R^{2}\right)$, suggesting a monolayer adsorption. What is more, the theoretical $q_{m}$ was in agreement with the experimental $q_{m}$ as shown in Figure 7.
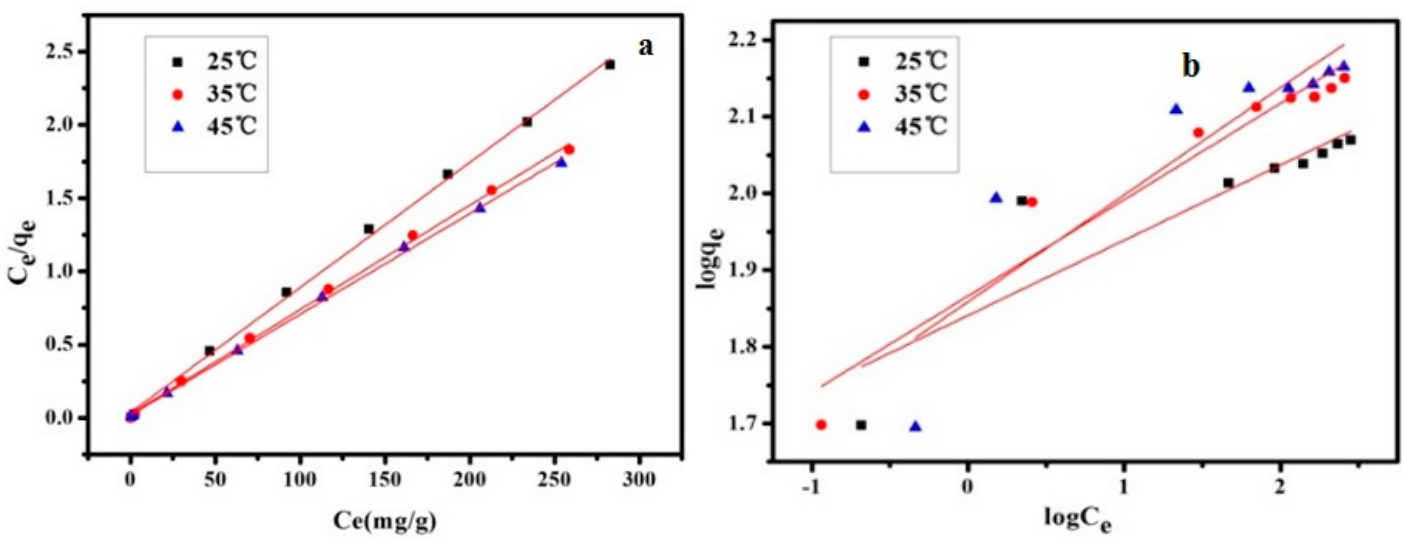

Figure 9. Isotherms of Bent-PAA for AB10B according to Langmuir model (a) and Freundlich model (b). Adsorption conditions: adsorbent dosage: $1.0 \mathrm{~g} \mathrm{~L}^{-1}$; at 298, 308 and $318 \mathrm{~K}$ and $\mathrm{pH} 3$; Contact time: 480 min; Dye concentration: $50-400 \mathrm{mg} \mathrm{L}^{-1}$. 
Table 2. Adsorption parameters of Bent-PAA for AB10B according to Langmuir model and Freundlich model.

\begin{tabular}{cccccccc}
\hline \multirow{2}{*}{$\boldsymbol{T}\left({ }^{\circ} \mathbf{C}\right)$} & $\boldsymbol{q}_{\exp }(\mathbf{m g} / \mathbf{g})$ & \multicolumn{3}{c}{ Langmuir } & \multicolumn{3}{c}{ Freundlich } \\
\cline { 3 - 8 } & & $\boldsymbol{R}^{\mathbf{2}}$ & $\boldsymbol{q}_{\boldsymbol{m}}(\mathbf{m g} / \mathbf{g})$ & $\boldsymbol{K}_{\mathbf{L}}(\mathbf{L} / \mathbf{m g})$ & $\boldsymbol{R}^{\mathbf{2}}$ & $\boldsymbol{K}_{\mathbf{F}}(\mathrm{L} / \mathbf{g})$ & $n$ \\
\hline 25 & 117.28 & 0.998 & 128 & 0.222 & 0.782 & 6.3 & 10.21 \\
35 & 141.6 & 0.998 & 142.86 & 0.269 & 0.929 & 6.46 & 7.97 \\
45 & 144.08 & 0.999 & 166.67 & 0.3 & 0.788 & 6.41 & 7.17 \\
\hline
\end{tabular}

\subsubsection{Adsorption Kinetics}

The mechanism of adsorption about the real adsorption process was investigated by pseudo-first-order and pseudo-second-order kinetic models, respectively.

The pseudo-first-order kinetic model is expressed as the following two expressions:

$$
\begin{gathered}
\mathrm{d} q_{t} / \mathrm{d} t=\mathrm{k}_{1}\left(q_{e}-q_{t}\right), \\
\ln \left(q_{e}-q_{t}\right)=\ln q_{e}-k_{1} t,
\end{gathered}
$$

where $q_{e}$, adsorption amount of the adsorbents for AB10B at equilibrium time; $q_{t}$ adsorption amount of the adsorbents for $\mathrm{AB} 10 \mathrm{~B}$ at any time; $\mathrm{k}_{1}$, the equilibrium rate constant of pseudo-first-order kinetic model.

The pseudo-second order process can be written as follows:

$$
\frac{t}{q_{t}}=\frac{1}{\mathrm{k}_{2} q_{e} 2}+\frac{t}{q_{e}}
$$

where $\mathrm{k}_{2}$ is the equilibrium rate constant of the pseudo-second-order model.

The fitted results are shown in Figure 10 and the related parameters obtained from the fitting curves are listed in Table 3. In the case of the pseudo-first-order kinetic model, $R^{2}$ was lower than 0.98 , while $R^{2}$ was over 0.99 in the pseudo-second-order kinetic model. Compared with the pseudo-first-order kinetic model, the pseudo-second-order kinetic model was more suitable for describing the adsorption process.
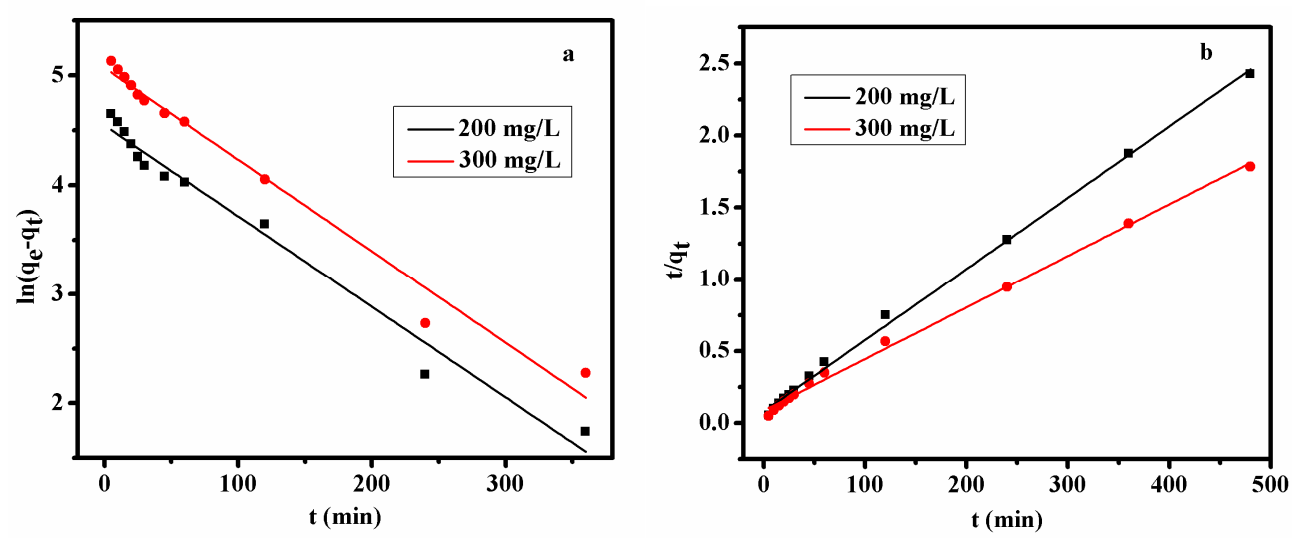

Figure 10. The linear fitted data according to pseudo-first order model (a) and pseudo-second order (b) Adsorption conditions: adsorbent dosage: $1.0 \mathrm{~g} \mathrm{~L}^{-1}$; at 298, 308 and $318 \mathrm{~K}$ and $\mathrm{pH}$ 2; Contact time: $480 \mathrm{~min}$; Dye concentration: 200 and $300 \mathrm{mg} \mathrm{L}^{-1}$. 
Table 3. The fitted parameters for the adsorption of Bent-PAA for AB10B.

\begin{tabular}{|c|c|c|c|c|}
\hline \multirow[b]{2}{*}{$\mathrm{C}(\mathrm{mg} / \mathrm{L})$} & \multicolumn{2}{|c|}{ Pseudo-First-Order Model } & \multicolumn{2}{|c|}{ Pseudo-Second-Order Model } \\
\hline & $R^{2}$ & $\mathrm{k}_{1}\left(\mathrm{mg}^{-1}\right)$ & $R^{2}$ & $\mathrm{k}_{2}\left(\mathrm{~g} \cdot \mathrm{mg}^{-1} \cdot \mathrm{min}^{-1}\right)$ \\
\hline 200 & 0.976 & 0.0083 & 0.998 & 0.00495 \\
\hline 300 & 0.979 & 0.0084 & 0.997 & 0.00359 \\
\hline
\end{tabular}

\subsubsection{Regeneration and Reusability}

The as-prepared adsorbent after saturated adsorption could be easily regenerated by using dilute $\mathrm{NaOH}$ aqueous solutions. The adsorption capacity for the reused adsorbent could remain $95 \%$.

\section{Conclusions}

Bent was functionalized with polyene propyl amine. The characterization results of XRD, FTIR, TGA, and SEM demonstrated that PAA was modified successfully onto interlayers of bentonite. Then the adsorption capability of Bent-PAA was tested against the removal of AB10B from water. Compared with Bent, the adsorption amount of Bent-PAA was excellent. The adsorption isotherm was also studied and the equilibrium data could be well described by the Langmuir adsorption isotherm model. Thus, it is expected that Bent-PAA will be an ideal adsorbent for the fast removal of AB10B from wastewater.

Author Contributions: W.G. is responsible for the whole design of the experiment. T.X. synthesized Bent-PAA. M.P. characterized the Bent-PAA. Y.D. do the adsorption experimental and L.W. fitted the data with Langmuir model and etc.

Funding: This work was financially supported by the National Natural Science Foundation of China (Grant Nos. 51672106 and 21802052) and the Key Research and Development Program of Shandong Province (Grant No. 2017GGX70104).

Conflicts of Interest: The authors declare no conflict of interest.

\section{References}

1. Rammel, R.S.; Zatiti, S.A.; Jamal, M.M.E. Biosorption of crystal violet by Chaetophora elegans alga. J. Chem. Technol. Metall. 2012, 46, 283-292.

2. Liang, Z.; Yan, C.-F.; Rtimi, S.; Bandara, J. Piezoelectric materials for catalytic/photocatalytic removal of pollutants: Recent advances and outlook. Appl. Catal. B-Environ. 2019, 241, 256-260. [CrossRef]

3. Sadegh, H.; Zare, K.; Maazinejad, B.; Shahryari-ghoshekandi, R.; Tyagi, I.; Agarwal, S.; Gupta, V.K. Synthesis of MWCNT-COOH-Cysteamine composite and its application for dye removal. J. Mol. Liq. 2016, 215, 221-228. [CrossRef]

4. Zhang, L.; Hu, P.; Wang, J.; Huang, R. Adsorption of Amido Black 10B from aqueous solutions onto Zr (IV) surface-immobilized cross-linked chitosan/bentonite composite. Appl. Surf. Sci. 2016, 369, 558-566. [CrossRef]

5. Wang, Y.; Xia, G.; Wu, C.; Sun, J.; Song, R.; Huang, W. Porous chitosan doped with graphene oxide as highly effective adsorbent for methyl orange and amido black 10B. Carbohydr. Polym. 2015, 115, 686-693. [CrossRef] [PubMed]

6. Zhang, L.; Hu, P.; Wang, J.; Huang, R. Crosslinked quaternized chitosan/bentonite composite for the removal of Amino black 10B from aqueous solutions. Int. J. Biol. Macromol. 2016, 93, 217-225. [CrossRef]

7. Hu, P.; Wang, J.; Huang, R. Simultaneous removal of $\mathrm{Cr}(\mathrm{VI})$ and Amido black $10 \mathrm{~B}$ (AB10B) from aqueous solutions using quaternized chitosan coated bentonite. Int. J. Biol. Macromol. 2016, 92, 694-701. [CrossRef]

8. Gao, Q.; Xu, J.; Bu, X.-H. Recent advances about metal-organic frameworks in the removal of pollutants from wastewater. Coord. Chem. Rev. 2019, 378, 17-31. [CrossRef]

9. Mo, J.; Yang, Q.; Zhang, N.; Zhang, W.; Zheng, Y.; Zhang, Z. A review on agro-industrial waste (AIW) derived adsorbents for water and wastewater treatment. J. Environ. Manag. 2018, 227, 395-405. [CrossRef] 
10. Sadat, S.A.; Ghaedi, A.M.; Panahimehr, M.; Baneshi, M.M.; Vafaei, A.; Ansarizadeh, M. Rapid room-temperature synthesis of cadmium zeolitic imidazolate framework nanoparticles based on $1,1^{\prime}$-carbonyldiimidazole as ultra-high-efficiency adsorbent for ultrasound-assisted removal of malachite green dye. Appl. Surf. Sci. 2019, 467-468, 1204-1212. [CrossRef]

11. Tian, S.-Y.; Guo, J.-H.; Zhao, C.; Peng, Z.; Gong, C.-H.; Yu, L.-G.; Liu, X.-H.; Zhang, J.-W. Preparation of Cellulose/Graphene Oxide Composite Membranes and Their Application in Removing Organic Contaminants in Wastewater. J. Nanosci. Nanotechnol. 2019, 19, 2147-2153. [CrossRef]

12. Zou, Q.; Li, H.; Yang, Y.; Miao, Y.; Huo, Y. $\mathrm{Bi}_{2} \mathrm{O}_{3} / \mathrm{TiO}_{2}$ photocatalytic film coated on floated glass balls for efficient removal of organic pollutant. Appl. Surf. Sci. 2019, 467-468, 354-360. [CrossRef]

13. Sajid, M.M.; Shad, N.A.; Khan, S.B.; Zhang, Z.; Amin, N. Facile synthesis of Zinc vanadate $\mathrm{Zn}_{3}\left(\mathrm{VO}_{4}\right)_{2}$ for highly efficient visible light assisted photocatalytic activity. J. Alloy. Compd. 2019, 775, 281-289. [CrossRef]

14. Yao, N.; Khusid, B.; Sirkar, K.K.; Dehn, D.J. Nanoparticle filtration through microporous ECTFE membrane in an alcoholic solution. Sep. Purif. Technol. 2019, 210, 754-763. [CrossRef]

15. Zhu, M.; Xiong, R.; Huang, C. Bio-based and photocrosslinked electrospun antibacterial nanofibrous membranes for air filtration. Carbohydr. Polym. 2019, 205, 55-62. [CrossRef]

16. Fu, W.; Zhang, W. Microwave-enhanced membrane filtration for water treatment. J. Membr. Sci. 2018, 568, 97-104. [CrossRef]

17. Harouna, B.M.; Benkortbi, O.; Hanini, S.; Amrane, A. Modeling of transitional pore blockage to cake filtration and modified fouling index-Dynamical surface phenomena in membrane filtration. Chem. Eng. Sci. 2019, 193, 298-311. [CrossRef]

18. Yang, R.; Li, H.; Huang, M.; Yang, H.; Li, A. A review on chitosan-based flocculants and their applications in water treatment. Water Res. 2016, 95, 59-89. [CrossRef]

19. Li, K.; Li, P.; Cai, J.; Xiao, S.; Yang, H.; Li, A. Efficient adsorption of both methyl orange and chromium from their aqueous mixtures using a quaternary ammonium salt modified chitosan magnetic composite adsorbent. Chemosphere 2016, 154, 310-318. [CrossRef]

20. Angelova, R.; Baldikova, E.; Pospiskova, K.; Safarikova, M.; Safarik, I. Magnetically modified sheaths of Leptothrix sp. as an adsorbent for Amido black 10B removal. J. Magn. Magn. Mater. 2017, 427, 314-319. [CrossRef]

21. Yang, R.; Li, D.; Li, A.; Yang, H. Adsorption properties and mechanisms of palygorskite for removal of various ionic dyes from water. Appl. Clay Sci. 2018, 151, 20-28. [CrossRef]

22. Wang, W.; Wang, X.; Song, C.; Wei, X.; Ding, J.; Xiao, J. Sulfuric Acid Modified Bentonite as the Support of Tetraethylenepentamine for $\mathrm{CO}_{2}$ Capture. Energy Fuels 2013, 27, 1538-1546. [CrossRef]

23. Liu, Y.; Cai, Y.; Yang, G.; Pan, Y.; Zhou, Y.; Zeng, G.; Tang, L. Chapter 2: Mesoporous carbon based composites for removal of recalcitrant pollutants from water. In Nanohybrid and Nanoporous Materials for Aquatic Pollution Control; Elsevier: Amsterdam, The Netherlands, 2019; pp. 31-61.

24. Abdukhalikov, K. Bent functions and line ovals. Finite Fields Appl. 2017, 47, 94-124. [CrossRef]

25. Chen, C.W.; Wu, W.J.; Zeng, X.S.; Jiang, Z.H.; Shi, L. Study on several mesoporous materials catalysts applied to the removal of trace olefins from aromatics and commercial sidestream tests. Ind. Eng. Chem. Res. 2009, 48, 10359-10363. [CrossRef]

26. Pan, J.; Wang, C.; Guo, S.; Li, J.; Yang, Z. Cu supported over Al-pillared interlayer clays catalysts for direct hydroxylation of benzene to phenol. Catal. Commun. 2008, 9, 176-181. [CrossRef]

27. Wolters, F.; Emmerich, K. Thermal reactions of smectites-relation of dehydroxylation temperature to octahedral structure. Thermochim. Acta 2007, 462, 80-88. [CrossRef]

28. Öztürk, N.; Tabak, A.; Akgöl, S.; Denizli, A. Reversible immobilization of catalase by using a novel bentonite-cysteine (Bent-Cys) microcomposite affinity sorbents. Colloids Surf. A Physicochem. Eng. Asp. 2008, 322, 148-154. [CrossRef]

29. Monvisade, P.; Siriphannon, P. Chitosan intercalated montmorillonite: Preparation, characterization and cationic dye adsorption. Appl. Clay Sci. 2009, 42, 427-431. [CrossRef]

(C) 2019 by the authors. Licensee MDPI, Basel, Switzerland. This article is an open access article distributed under the terms and conditions of the Creative Commons Attribution (CC BY) license (http:/ / creativecommons.org/licenses/by/4.0/). 